\title{
WARTOŚĆ „SEPTUAGINTY” W ROZUMIENIU ŚW. HILAREGO Z POITIERS
}

Mało znany w Polsce św.IIllary z Poltiers, zwany powszechnie "Atanazym Zachodu" nalezał do najpowazniejszych postaci IV w. 1 najbardziej oddziaływujących na późniejszych zachodnich autorów kościelnych. Jego wielkość ocenia slį zwykle przez pryzmat podstawowych 1 centralnych problemóv teologii, którymi siz zajmowal oraz głębi myś11 egzegetyczriej, jakie pozostawi w swych komentarzach do wybranych przez siebie ksiąg Plsma św. Ujawnia się ona jednak równiez 1 \% tych jego wypowiedziach, w kórych ubocznte zajmuje wasne stanowisko względem szczegółów teologicznych 1 egzagetycznych. Do takich szczegółów egzegetycznych należy nievatpliwie pogląd na temat "Septuaginty". W niniejszym artycule "1n honorem" znakonttego znawcy literatury patrystycznej 1 fllologa, ks. Andrzeja Bobera, pragnę zwrócić uwage na te wypowiedzi śr.illlarego, w których mówi o Septuagincie; 8 q one same $w$ sobje skromne, podkreślaja jednak ponadczasowa wartość Tradycj 1 interpretacj 1 Pisma św. ${ }^{1}$

cijan ${ }^{2}$ wyjątkowym autorytetem. Począwszy od śm. Justyna, a skonczymszy na św. Augustynie, ojcowle I ościoła traktowali Septuaginte jako przekład natchniony ${ }^{3}$. Idłc za Ariotobulem, Józefem Flawiugzem 1 Fi-

1 Artykuł ten jest fragmentele rozprawy: "Czynnik1 kształtujące sens biblijny w ujęciu śiv. Hilarego z Poitiers", która została złozona do druku if wydawnictwio ATK: "Studia Antiquitatis Christianae".

2 Por. Augustinus, De c1vitate $D_{\theta 1}$ XVIII, 44, CC 48,641, tłun. W.Kornatorski /0 paístwie §ozym, Varszawa 1977, t.2,372: "Totez 1 Ja medle mych skromych możliwości podłzając śladami Apostołów, którzy powoły rodzajów tekstów, to jest podzug tekstón hebrajskich i Septuaginty, uznałem za stosowne uciekać sig do obu powag, gdyz obie sa jedną, w dodatku boską".

3 Tamze XVIII, 43, CC 48,639, Kornatowsk1, t.2, 370 "Bo ten sam Duch, który byl prorokach, gdy to mówili, byz tez w siederadziesiegciu męzach, gdy to tłumaczyli. z pewnościa mógł on tez z boskiej pomag1 mówíc coś innego, tak jakby ów prorok powiedzial jedno 1 drug1e, gdyz jedno 1 drugie mówit tenże san Duch; mógł równtez mónié to samo innym sposobem, tak by w miejscu, gdzle slowa są odmienne, kazdy dobrze rozumiejący tekst jasno widzlaz lch jednakie znacze- 
lonem tacy chrześcijańscy pisarze jak: Pseudo-Justyn, św. Ireneusz, Klemens Aleksandryjsk1, sw. Cyryl Jerozolimski, Eplfaniusz, św. Augus tyn rozwijali 1 wzbogacal 1 róznymi szczegółami cudowne okoliczności powstania Septuaginty, wypowiadajac tym sposobem przekonanie o boskim charalsterze przekładu siedemdziesięciu tłuruaczy ${ }^{4}$. Mało znany pogląd św. Hilarego na temat Septuaginty zawarty jest przede wszystkim w jego "Traktatach do Psalmów". Wypowiedzi tych traktatów moźna uporządkować w dwie grupy, z których pierwsza zwraca uwage na autorytet, druga natomiast na doskonałość tłumaczenia z racji jego interpretacyjnego charakteru ${ }^{5}$.

\section{Autorytet Septuaginty}

Septuaginta posiada u Biskupa z Poitiers niepodważalny autorytet, poniewaz powstaía wradycji; konkretnie tradycji Mojzesza. Siedemdziesizciu tłunaczy pozostawało w łączności z tradycja Mojzeszową 1 w kontekście tej tradycj1 dokonało przekładu Pisma św. z oryginalnego języka hebrajskiego na język grecki. Ten zasadniczy argument powtarza sia w "Traktatach do Psalmów" w róznych sformułowaniach 1 przy róźnych okazjach oraz posiada dla Hilarego zasadnicze znaczenie ${ }^{6}$. Mówl on o nim:

"W tym bowlem czasie, kledy w pełni obowizzywało Prawo, zanim jeszcze narodzit sie Jednorodzony Syn Bozy, odwieczny Bóg - Słowo jako człoriek, na prośbę króla Ptolemeusza, siederdziesieciu starszjch przetłumaczyło z jozyka hebrajskiego na greck1 ksiggl Starego Testamentu. Mojżesz bowiem postanowił, aby w całej Synagodze było siederadziesięciu doktorów. On to, chociaz spisaz treść Przymierza, to jednak spośród tajemniczych przepisóv Prawa, te naj-

nie; mógł wreszcie coś opuścić lub coś dodać, aby 1 tyu sposobem dać do poznania, iz praca tłumacza kierowała nie zwyczajna ludzka zależnośc krapujàc go siowani, lecz raczej boska moc, stóra przenikała umyst tłunaczącego 1 nim rzadziła".

4 A.Pelletier, Introduction à Lettre d Aristée à Phllocrąte, SCh $89,78-98$; P. Benô̂t: L' Inspirations des Septante d'après ies Péres, w: L Lllomme devant Dieu. Mélanges offerts au pere II. de Lubac, Paris 1963, 169-187; D.Barthélemy; Eusebe, La Septante et "Les autres", w: La Bible et les Pères, Colloque de Strasbourg Cytuje: Tractatus super Psalmos, od. A.zingerle, CSEL 22, Vindo-
bonae 1891/InPs/.

Tego rodzaju argumentacja w okresie patrystycznym należy do nie- 
bardziej ukryte wyjaśnił siedemdziesięciu starszym z ludu, 7 którzy nastôpnie, po jego śmterci mieli być nauczycielami"t?

Plerwsza częśc wypowiedzi wyraźnte nawizzuje do rozpowszechnionej opinil o niezwykłych okolicznośclach powstanla Septuaglnty. Druga część natomlast wydaje slę być oryginalna 1 nie znajdująca wyraźnego precedensu w literaturze przedhilariańskiej ${ }^{8}$. Pierwsza częśc w porównaniu ze śwladectwami judalstycznymi 1 chrześcijańskimi zdradza charakterystyczne elementy dla pracy nad św1ętym tekstem u B1skupa z Poitiers. Nawiazuje wprawdzie do rozpowszechnionej tradycji, ale podniosły ton początku wypowiedzi wskazuje na waźność omawlanego zagadnienia. Czytelnika jednak uderza kontrast pomiędzy uroczystym tonem pierwszej częśc1 zdanta z suchą 1 kronikarskż relacją drugiej części ${ }^{9}$.

Hilary nie wspomina o tych nadzwyczajnych okolicznościach powstania Septuaginty, Jakio przekazuje oszczędnte jeszcze "L1st Arysteasa do Filokratesa". "Swiadectwo" Arysteasa wabogacili wadzwyczajne szczegóły Filon Aleksandryjski, Józep Flawiusz, a z pisarzy chrześcijańskich: św. Justyn, siv. Ireneusz, anonimowe p1smo z II lub

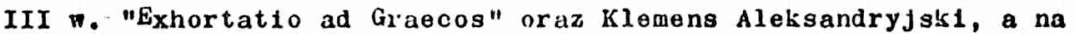
Zachodzle Tertulian ${ }^{10}$. Hilary tymczasem nie mówi o sledemdziesięciu dwóch starszych, Jak l1st Arysteasa, lub wypowledzl Filona, Józefa

$11 \mathrm{cznych}$ myjatków.

7 InPs 2,2 , CSEL 22,38 .

8 Cudowna zgodność dzieła tłumaczy, patrystyozni pisarzo wyjaśniall "darem proroczego ducha"; Illary tego ducha przypisuje nie jednostkom, lecz instytucji, do której one nalezaly.

9 InPs 2,2, CSEL 22,38: "Med11s namque leg1s temporibus" - wprowadza nastrój podniosky, alscentuje epokowe znaczenie prośby Ptolemeusza; "erat auteti $1 \mathrm{am}$, a Moyse institutum" - relaoja raktu powołania instytucj1 doktorów dla nauczania 1 interpretowania Prana.

10 List Arysteasza akcentuje fakt, te Siedemdziesieciu przetłumaczyto Biblie 72 dniach; Filon dodaje: "nie bez woll Boga", pod wpłyien "natchnienia boskiego", "niowidgialnego tchnienia", tłumaczy nazywa "hierofantain1 1 prorokami"; 2ydz1 ustanow111 święto, któro obchodzono na pamlątkę dokonanla przekładu; Józef Flawiusz podkreśla wykształcente tłumaczy; św. Justyn dopuszczając 918 błodu chronologicznego/Ptolemeusz pros1 o tłumaczy króla Heroda/ podkreśla cudowne rozpowszechntente się Septuaginty; śr. Ireneusz mspomina $c$ "rozdzieleniu tłumaczy czasie lch pracy translatorskiej, zgodność wyników pracy; "Exhortatio ad Graecos" mówi o krótkim czasie trwanla pracy 1 zgodności przekładóm pod wzgledem trés- 
Flawiusza, czy Tertuliana, lecz tylko o "Slelemdziesięciu". Cała swojz uwage skupia na tradycji, z której wyrasta autorytet Septuaginty. Lączy siedemdziesizciu tłumaczy z instytucja "starszych", to jest tych, których powołał Mojzesz do wyjaśniania objawionych tajenntc boskich. Mojżesz wprawdzie pozostawiz na piśmie otrzymane od Boga Objawienie, alo interpretacje spisanego objawienia pozostawil siedendziesiąciu doktorom, których ustnie pouczył, jak należy rozumieć tekst oraz wyjaśnłł tajemnice Prawa ${ }^{11}$. Waźnym argumentem na korzyść nauczycielsiciej roli "doktorów" wtajemniczonych ustnie w spośbb rozumienta Prawa promulgowanego przez * tajniki kryjące się poza litera pisma, stanowi fakt odwozymania sie do nich|Chrystusa. Ten ostatni argument odgrywa zasadnicza role na korzyść kompetencji siedemdziesięc1u tłumaczy oraz autorytetu $1 \mathrm{ch} \mathrm{dziera}{ }^{12}$.

Rozpracowując dalej podstawy autorytetu Septuaginty Biskup z Poitiers przytacza dalsze dwa argumenty. Po pierivae: tłumaczenie powstało przed Chrystusem ${ }^{13}$, po drugie: sam1 tłunacze posiadali wszelkie kompetencje, dziegki którym dzieło 1ch osiagnęło autorytet bez precedensu ${ }^{14}$. Pierwszy argument posiada charakter apologetyczny. Można w nim bowiem dostrzec bądź wyraźna dyskusje na temat autorytatywnego 1 normatywnego tekstu tłumaczenia Pisma siw., bądz aluzJe do historycznego sporu odnośnie do oblektywności przekładu dokonanego przez siedemdziesięciu ${ }^{15}$. Niezaleźnie od tego z kín polemi-

c1 1 słów; Klemens Aleksandryjski nazywa tłunaczy "prorokami Greków"; Tertulian nazywa prace tłumaczy "dziełen opatrznośc1 Boga"; por. A.Pelletier, dz.cyt., 78-98.

11 InPs 2,2, CSEL 22,38 .

12 InPs 2,2, CSEL 22,38: "Cuius doctrinae etiam dominus in evangelis meinit".

13 InPs 2,3, CSEL 22,39: "Primum, quod ante adventum corporalem domint transtulerunt".

14 Tamże: "dehinc, quod ipsi 1111 principes doctoresque synagogae ... non potuerunt inprobabiles esse arbitri interpretandi, qui certissimi et gravissimi erant auctores docendi".

15 Por. J.Danièlou, Origène, Paris 1948, 139-142; D.Barthŕlemy, 
zuje, Hilary wyraźnie zaznacza, iz powstanie Septuaginty przed przyjéciem Chrystusa nadaje jej charakter obiektywny 1 pozbawia podejrzeń, 1z została ona sporządzona na uzytek chrześcijański, czy też powstała z jakichkolwiek z góry przyjętych załozen ${ }^{16}$. Fakt ten jest tym większej wagl, ze siedemdziesięciu tłumaczy przed Chrystusem nie tylko przełożyło "Ksiege Psalmów", lecz nadto w duchu chrześc1jańskim dokonało pewnego rodzaju interpretacj1 w oparciu o ustny przekaz wiedzy, otrzymanej od Mojzesza. Tłumagze uporządkowali bowiem cały Psałterz, zaopatrzyli possczególne psalmy wevne znaki, które wskazuja na $1 \mathrm{ch}$ sposób rozumienia. Słusznośc1 tej interpretacji dowodzi to, iz Chrystus przez tajemnice wcielenia, mąki, zmartwychwstania wylkazał, $1 \dot{z}$ tylko w ten sposób można rozumieć Psałterz, a walszej konsekrencjl całe Pismo sw. Starego Testamen$\mathrm{tu}^{17}$.

Autorytet Septuaginty wynika dalej z kometencj1 siedewdziesięciu tłumaczy. Jałs zaznaczono wyżej, źródłew $1 \mathrm{ch}$ autorytetu jest nie tyle znajoność Prara spisanego przez Mojzesza, lle ustne przekazanie rozunienia tego Prawa. Jak zawsze, tak 1 dla tego oryginalnego patrystycznego twiordzenia, Ililary znajduje podstawe o tekstach Pisma św. Na sposúb bowiou rabinistyczny laczy z sobł " jednz całość dva tekity starotestamentalne $/ V_{j} 11,16$ i Lb 24, $4 /$, oraz jeden nowotestanentalny / At 23,2/, który potwierdza, ze instytucja "starszych" 1 "doktorów" trivała nieprzerwanie od Mojżesza do Chrystusa. Najistotniejsze słowa argurantu starotostamentalnega sa następujace: "Yezm̧ z ducisa, ktúry je:st w tobie 1 dam im". Siedendziesizclu otrzymując drog: sukcesj1 "ducha", który był w Mojzeszu hit 23,2/, "osi.łơng̨1 wiedze poznan1a rzeczy tajennych zgodnie z duchowa tradycji Mojzesza", zrozumieli treśc psalnów "dzigki wiedzy duchowej 1 niebieskiej", zdobyl1 takiz "znajomość prawa 1 proroków", 12 mogli wyjaśnić dwuznaczności przepisów, mogli dokonać "poprawnego 1 duchoirego" przelcładu, "pozostawić sens duchowej wiedzy"18. Akcentujac ścisły zwi zzek siedeadziesięciu tłumaczy z trady-

16 InPs 2,3, CSEL 22,39: "Nec adulatio interpretandi adhibita tempor 1 arguetur, tanto anteriore interpretationts aetate".

17 InPs 2,3, CSEL $22,39-40$.

18 InPs 2,3 ; Instructio Psalinorum 8, CSEL $22,4019$. 
cja Mojzesza autor wyraza przekonanie, ze lch dzieło w wielu miejscach przewyżza nawet sam oryginał hebrajsk1, poniewaz po pierwsze uściśla "przepisy 1 diuznaczności" tekstu oryginalnego ${ }^{19}$, po drugie nie tyle tłumaczy, 1 le wiernie przekazuje "duchowa doktrynę" tekstu ${ }^{20}$, po trzecie z redakcji wydarzeń biblifnych nie tyle ukazuje loh treśc, 1le znaczenie religijne ${ }^{21}$, po czwarte kierując sie "wiedza duchowa" siedemdziesięciu tłumaczy posłużyo sie takimi terminami, jakie same przez sia wprowadzaja w boskie tajennice 22 .

\section{Egzegetyczny charakter}

Dzieło siedemdziesizciu tłumaczy jest wiec nie tylko przekładein, lecz równocześnie komentarzem, a więc posiada charakter egzegetyczny. Hilariańskie uwagi odnośnie do egzegetycznego charakteru Septuaginty dotyczi najpierw zewnetrznej, następnio wewnętrznej strony Psałterza 23. W pierwszym przypadku autor mówi o uporz łdkowantu psalıów, wrugim zaś o pewnych znakach, które kierują sposobea rozumienia poszczególnych psalmów. IF "Instructio Psalmorum" Hilary zarysowuje trzyetapowy rozwój Psarterza: Początkowo psalmy nie stanowiły zadnego zbioru, istniały odrębnie ${ }^{24}$. Według tradycj1, rozproezone 1 1stniejące odrębnie poszczególne psalmy złz̨czył najpierw w jeden zbiór Ezdrasz. Ale 1 ten zbiór nie był uporządkowany według jednego, jasnego kryterium ${ }^{25}$. Trzeci 1 ostatni etap rozwoju Psakterza miax miejsce za czasów Ptolemeusza Filadelfa, kiedy siedemdziesięciu dokonało nie tylko przekładu, lecz nadto uporząkowało wsystkie psalmy według kryterium ich duchorvego rozumienia: nie było to jednak kryterium chronoloriczne. Tak, np. psalm 50, chociaż omawia wydarze-

19 InPs 2,$2 ; 2,2, ; 142,1 ; 143,2$, CSEL $22,39,40,805,814$.

20 InPs $2,2, ; 143,1, \operatorname{CSEL~22,40,814.~}$

21 InPs 59,1, CSEL 22, 192-193.

22 InPS 2,2, CSEL 22,39.

23 InPs 2,3, CSEL 22,39-40.

24 Instructio 8 ; InPs $2,3, \operatorname{CSEL} 22,9,40$.

25 Instruct10 8 , CSEL $22,9$. 
nia późniejsze niz̀ psalm 51, to jednalc został przed nim umieszczony. Nie było to równiez kryterium autorúw psalmów, poniowaz istnieje wediug tradycj 1 utarta zasada ustalanta autorstwa poszczególnych Psalmói ${ }^{26}$.

Na pytanie o kryterium uporządkowania psalmów Bisicup z Poitiers odporiada wprost: "Według działania l1czb doskonałych"; według "mocy 1 tajemnicy zawartej w liczbie"; lub wreszcie, rozumiejąc treśc psalmów za pośrednictwem "duchowej 1 niebieskiej wiedzy" Siedemdziesizciu uporządkowało wszystkie psalmy według porzłdku liczbowego, przypisując poszczególnym psalmom takie działanie duchowe, jakie oznaczajz $1 \mathrm{ch}$ kolejne $11 \mathrm{czby}{ }^{27}$. Tego rodzaju odporiedź oplerajzca sie na starożytnej syubolice liczb lep̣ej rozumiejił współcześni twórcy komputerów niz teologowie 1 bibliści 28.

Analizujac wypowiedzi Blskupa z Poitiers na temat "liczb doskonałyci" naleźy zauważyć, ze chociaźs sposób patrzenia na liczby falstycznie pochodzi z ducha czasu, to jednak ich treśc, Jakił $1 \mathrm{~m}$ przypisuje, posiada zdecydowante podłoże biblijne ${ }^{29}$. Refleksja naszego autora skupia się na dwóch zasadniczych cyfrach: 71 8. Obydwie cyPry miazy być punktein wyjścia dla Siedemazlesięciu w ustaleniu kryterium porzzukującego psalmy. Obydwie łączy z instytucjami starotestamentalnyini 1 maj czasynowotestamentalne ${ }^{30}$. Cyfra bowiem 7 zajmuje uprzyirilejowane miejsce u Żydów bądż z racjl siódmegro dnia tygodnia, bądź roku jubileuszowego31. Połzczenie cypry $7 \mathrm{z}$ szabatem oraz rokiem jubileuszowym nastąpilo zaś dlatego, ze szabat symbolizuje "zachowanie prawa", które przygotowuje odpoczynek w siódmyul dniu tygodnia32. Cyfra

26 Instructio 8, CSEL 22,9-10: "Septuaginta seniores... spirital1 et caelesti scientia virtutes psalmorum intellegentes in numerum eos atque ordinem redegerunt; Por. tanze 3,9,10, CSEL 22,4,10.

27 Instructio $8, \operatorname{CSEL} 22,10$ : "singulis quibusque numeris pro efficten. tia sua et absolutione perfectis perfectorum et efficientium psalmorum ordinem deputantes; por. InPs 150,1, CSEL 22,870.

28 Por. H.slarrou, Saint Augustin et la iln de la culture antique, Paris 1958, 251-275.

29 Por. N.J.Gastald1, Ililario de Poitiers, Exegeta del Salterio, Paris 1969, 105-112.

30 InPs 119,6: Instructio $8 ; 12 ; 13 ; 14 ;$ InPs 150,1, CSEL 22,547,9, $11,12,870$.

31 Instruct10, 12, InPs $119,6,150,1$, CSEL $22,11,547,870$. 32 Instructio $16, \operatorname{InPs} 118, \operatorname{Sin} 4, \operatorname{CSEL} 22,13-14,537-538$. 
natomiast 8 przedłuża starotestanentalny tydzień o jeden dzień, który uchodził równteż za pierwszy dzleń tygodnia ${ }^{33}$. Mok zaś jubileu szowy nie jest niczym innym, jak z jednej strony rokiem dodanym do suny lat, w skład których wchodzi cyera 7 pomnoziona przez 7 tygodn1 lat, z drugiej strony rozpoczyna now serie tygodni lat 1 jest pierwszym rokiem w nowej pięćdziesiątce lat ${ }^{34}$. Wniosek Hilarego z powyższych rozważá jest egzegetyczny: Siedendziesięciu obierając cyfry 7 i jako kryteriun porządkujące psalmy wskazywali bądź na pełnlę ewangeliczną, bądź na czasy eschatologiczne ${ }^{35}$.

Lącząc obydwie cyfry z instytucjami starotestamentalnymi oraz rozumiejac lch symbolizm, Siedemdziesigciu nadało kaźdemu psalinowi taki numer, Jaki odpowiada jego duchowej treśc1. Tak, np. psalm 8 zapowiada czasy eschatologiczne. Podobną zapowiedź znajduje s1e tych psalmach, których znajłuje się ósemka, a więc: 18,80,83,118. Ponadto słuszność tego przekonania wzmacnlaja, według H1larego, same tytuły wyszczególnionyci psalmów, które noszą nałłówek: "Dla tłoczni", to zaś oznacza przygotowante naczyń na nowe owoce czasów ewangelicznych ${ }^{36}$. Psalm 50 otrzymal liczbę z racjl zawartości treśclowej, której syubolen jest $11 \mathrm{czba} 50$. W roku jub1leuszowym bowlem otrzymywało się odpuszczenie grzechów, psalm zaś 50 jest modlitwa - odpuszczenie grzechów ${ }^{37}$. Połączenie cyfr 718 wyjaśnia 15 psalmó, zwanych "pieśniami stopni". Do miejsca "Swiętego świłtych" wstępuje się po pį̨tnastu stopniach, to jest poprzez przestrzeganie prawa oraz przez zachowanie doskonałości ewangelicznej, 1 taka właśnie treść "wstępującă" kryja psalmy zwane "pieśniami stopni"38. Kryterium liczbowe posłużło Siedendziesieciu równiez do podziału całego Psałterza na trzy czáści: pierwsza plęćdziesiątka psal. mów mówi o wyznawaniu 1 odpuszczeniu grzeciór zgodnie z przepisami

33 InPs 119,6; Instructio 12, CSEL $22,546-547,11$.

34 InPs 118 Sin 4-5, CSEL $22,537-538$.

35 Instructio 12; InPs 119,$6 ; 150,1$, CSEL $22,11,517,870$.

36 Instructio 13, 14, CSEL 22, 12 .

37 Instructio 10, CSEL 22,10 .

38 Instructio, 16, CSEL 22, 14 . 
prawa; druga vskazuje na oroc odpuszczanła grzechów, to jest na życle według sprariediłrości bożej; trzecia wreszcie traktuje o lrólestwie Bogazałożonyin moca Chrystusa 1 zrealizowanym w całej pełni w świetych po zmartwychwstantu unarłych ${ }^{39}$. Konkretyzujac swe rozważania IIilary stwierdza, że pierısze 50 psalmów omawia chrzest, drugie zmartwychwstanie, trzecie przemiane 1 uduchowienie natury ludzkiej. Pierwsza prowadzi do zycia w niewinności, druga do zbawienia i zmartwychwstania, trzecia do urielbienia 40 .

\section{Znaki duchowego rozunienia}

Egzegetyczne dzieło Siedemdziesizciu nie ograniczało sie tylko do zewnętrznego uporządicowania Psałterza. Ont bowlon oznaczyli poszczególne psalmy tytułani 1 nagłórkani, następnie usunęl1 dwuznaczności terminór hebrajskich przez ich jednoznaczne odpowtednik1 języka greckiego, wreszcie umieścill wernaterz psalmu pewne znaki, które ułatwiajiz czytelnikowi zrozunienie ich treści.

Przy allalizie wypowiedzi odnośnie do tytułów psalión narzucają sie trzy ogólne uwag1: po plerwsze dla Ililarego wypozażenie psalmów w tytuły jest dziełera wył.zcznie siedemazlesįciu tłumaczy; po drugie tytuły st pewnego rodzaju hasłem tresici lanego psalmu; po trzecie różnorouność tytułów posiada zawsze funkcje egzegetycznq ${ }^{41}$.

\$ypowiedzi na temat tytułów psalmów wskrazuja na dwa 1ch rodzaJe: pierwsza grupa tytułów wskazuje z punktu widzenia treści na okoliczności historyczne psalmu, jejo autora, czasu powstania; druga natomiast przekazuje uwagi na temat sposobu rozumienia, czyl1 wskazórki metodyczne. IV plerwszym przypadku IIilary mówi, ze Siedemdzlesigciu umieściło w tytułach paalinón tylko te dane historyczne, które prowadzł uwaźnego czytelnika do odczytanta takiego sensu, Jak1 Bóg zamknłł w psalmie ${ }^{42}$. "yinienienie w nagróvkach psalmu tmion

39 Instructio 11, InPs 150,1, CSEL 22,10-11,871.

40 InPs 150,1, CSEL 22,871: "Ac sic omnia, baptismun, resurrectio, denutatio continentur, cum prima nos libri huius quinquagesima regeneret ad innocentiam, sequens ad fudicium innocentiae resurrectione perducat, tertia in naturam spiritus et lauden constituat"; Por. Instructio 11, CSEL 22,11.

41 Por. InPs $142,1,143,1,145,1,146,1$; De Titulo Ps 9,2; InPs 51, $1 ; 150,1$, CSEL $22,805,813,840,844,75,96,870$.

42 Por. InPs 119,1,544; Instructio 17 ; InPs 55,$1 ; 63,1 ; 68,1 ; 141 ; 1$, 
bądź autorów, bąd ó osób odgrywających historyczną rolq, o których mów1 interpretorany tekst, bądz wreszcie wyposazenie tych imion zalmk1, wskazuje na profetycznaz wartość poszczególnych psalmów oraz realizacje toj wartośc1 w Chrystusie 1 Kośclele ${ }^{43}$. Sa tytuły psalmów, które oprócz swego bezpośredniego, posiadaja drugle bardziej reflecsyjne 1 głębszo znaczenie. Przejście zaś od plerwszego do glebbzego znaczenia nie jest dowolne 1 subiektywne, alo posiada zawsze uzasadniente biblijne, najczęśclej w plsmach nowotestamentalny $\mathrm{Ch}^{44}$.

i tytułach mskazujacych wprost na sposob rozumienia psalmu Hilary wyrózniaz trzy kategorie: "1n finem", to jest wyrazonie, wskazujice na to, ze treś paalmu nalezy rozumied przecinstawieniu do zyeia doczosnego, lub zo treśc jego stanie sie zrozumiała dopiero $"$ ostatnich wierszach danego psalmu ${ }^{45}$; następnie tytury: "psalnus" 1 "Canticum" oraz ich zestariente, określaja z jednej strony spos6b artystycznego wykconania psalmu, z druglej zaś sposób dojśça do poznania tajemnio Bozych: bqudz przez poznanie, z którego wonsekiencj1 wyntka przemiana zycia, bąú poprzez zmiang zyola prowadzaca do poznania ${ }^{46}$; wreszcie psalmy z tytuzem "Canticum graduum", mówlaz, ze królestwo niebieskie mozna osiagnąé tylko poprzez zachowante Prawa 1 Bwangel11 47 .

Nie wszystkie psalmy posiadaja tytuły, a tym samym nie wszystkie ukazuja sposób rozumienia lch treści. Odnośnie tych psalmów Biskup z Poitiers dyktuje zasadę, 1 z należy je rozumié $n$ kontekście miary oraz światza Ducha $S_{W}$. $T_{a}$ jednal zasada nio wprowadza niebozpleczeństwa dowolnośc1 1 sublektywnego sposobu rozumienia tekstu śtviętego, pontewaz oplera się na ścísle określonych prawach rozumienia tekstu 48 .

CSEL $22,544,14-15,162,224,313,79 S$.

43 Por. InPs 51,2; 52,1; 53,2; 58,1; 59,$1 ; 69,1 ; 141,1 ; 142,1$, CSEL $22,96,118,135,181,191,341,799,805$.

44 InPs 68,$1 ; 91,1 ; 119,6 ; 141,1 ;$ Instruct10 22, CSLL 22,313,346, $547,799,17$.

45 Por. De Titulo Ps 9,2; InPs 13,2; 51,1; 52,1; 55, 1; 63, 1; 64, 1; Instruct1o 18 , CSEL $22,75-76,79,96,118,162,224,233,15$.

46 Instruct 10 19; 20 , CSEL 22,15-16.

47 Instruot10 16, CSEL $22,14$.

48 Instruct10 21; 22, CSEL 22,17-18. 
Praca egzegetyczna Siedendziesięciu dotyczyła równiez modyfikacji 1 ulepszenta samego tekstu Pisma św. Hilary mówi o usunięciu "druznaczności" hebrajskich słów. Jako przykład podaje słowo "Boresith", które posiada trzy znaczenia: "In principio", "1n capite", "in filio"49. Siedemdziesizciu opowiedziało sie za wyrazeniem "in principio". Nadto Hilary nów1, ze Siedemdziesięciu udoskonal1to tekst swiety. Jest to jednak tylko twierdzenie przyjatte od poprzedników, które Hilary ani nie ilustruje przykładami, ani tez nie uzasadnia ${ }^{50}$.

Stedendziesięciu wreszcie według llilarego umieściło wewnątrz psalimu pewne znalsi, które ułativiaja zrozumienie jego trésc1. Konkretnie mówiły tylko o tzw. "diapsalmach", przypisujac im odmiennie od innych autorów trzy Punkeje: podkreślenie zmlany sposobu śplemania lub granta na instrumencie, zwrócente uwagl na zmianę podmiotu oraz sensu vypowiedzi autora psalinu ${ }^{51}$. Poniewaź ani tekst Septuaginty, ani jej łacińskie tłunaczenie nie przekazało zadnych znaków odnoś nie do sposobu ich śplewania czy grania na instrumencie, diapsalma praktycznie posiada tylko znaczenie zmiany podmiotu 1 sensu psal$\mathrm{mu}^{52}$. Wedzug Hilarego oznacza ona po pierwsze zmiane podmiotu zdania, a nówi zc przykładowo: na początku psalmu przemawia psalmista, dalej zaś przez jego usta Apostołorie ${ }^{53}$; po drugie zinian̨̧ osoby, do której psala przeluawia, np. na pocz atku psalm zwraca ole do źydów, dalej do wszystkich narodó ${ }^{54}$; po trzecie, 1 to najczęściej oznacza zmian̨ sensu, np. najpierw pojawia sį sens historyczny, literalny, dalej zaś sens duchowy oraz jego aspekty: chrystologlczny, eklezjalny, czy eschatologiczny ${ }^{55}$; po czwarte wreszcie diapsalma ma znaczenie pewnej netody dydaktycznej. Przerwa bowlem w wykładzie pomiędzy

49 InPs 2,2, CSEL 22,39 .

50 Por. InPs 2,$2 ; 54,11 ; 55,1 ; 65,12 ; 118$ He $7 ; 138,10 ; 143,2$, CSEL $22,38,153,162,257,404,730,814$.

51 Instructio 23, CSEL 22,18 .

52 Odniennie o diapsalmie mówi św. Hieronim w liście do Marcelli, por. Epistola XXVIII, P1 22,433-435, tiam. J.CzuJ/Listy, Warszawa 1952, t.1, 174-177.

53 InPs 65,$9 ; 65,16 ; 65,27 ; 66,4 ;$ Instructio 23 , CSEL 22,254,259, $267,271,18$.

54. InPs 53,$9 ; 54,10 ; 65,16 ; 65,12 ; 65,27 ;$ CSEL $22,141,154,259,257$, 267.

55 InPs $51,11-12 ; 51,19 ; 54,10$, CSEL $22,104-105,110,154$. 
Jedn t a drug:t myślił, lub jakaś dygresja zaostrza uwagê 1 przygotowuje na przyjęcie nowej i glębszej treści ${ }^{56}$.

Gdybyśny chcieli krótko odpowiedzleć na pytanie czym jest dla śr. ililarego "Septuaginta", to musielibyśmy stivierdzić, lź jest ona dia niego normatyrnys 1 autoryatywnow tekster Pisna sis. Jest nim takir z dwóch racj1: po plerwsze autorytet dzieła siedemdziesięciu tkw1 przede wszystkin is tyro, ze tłuracze byl1 nosicielami 1 przelazicielami całej duchowej rzeczywistości zapoczitlowanej przez Mojżesza. Wychodząc z tej tradycjl dokonali przekładu przed przyjściem Chrystusa/dlatego nie moźna 1ch posadzać o uleganie wpłyrow1 chrześcijaństwa/, który san a później 1 jego apostołow1 zaakceptowali ich dzieło. Po drugie, tkwizc w tradycji Mojżeszowej 1 dokonując odpowiadającego ich kompetencjom oblektywnego przekładu, stworzyli podstawy do autorytatywnej egzegezy przez całe - powiedziny techniczne wyposażenie Psałterza: uszeregowante 1 uporażdcowante psalnów, podział na trzy części, różne nagłówki 1 tytuły oraz diapsalmy. Ta "techniczna" strona dzlela Siedendziesiçciu jest waznym czynnikiem, nskazującym czytelnikowi na sens Psałterza. Po trzecie, praca Siedemdziesizciu tłumaczy, czynt z Biblil pod wzø ledem sensu - wiele czytelniejsze dzieło, niz san oryglnat hebrajski, ponieraz ten ostatini może być zrozumiały tylko w ośrodlsach żyows'sich, Septuaginta natomiast jest czytelna wazdym środowisku.

Z hilarialisich uwag na temat Septuaginty nasuwaji sie diva praktyczne wnioski: po plerwsze, ze zrozumienie nawet najstaranniej wydanego tekstu świłtego oraz wierny 1 dobry jego przeklad zależy nie tylko od takich dziedzin, jak filologia, historia czy róznego rodzaju krytyka, lecz przede wszystkin od kościelnej tradycji biblijnej, 1 od środowiska religijnego. Hilary podkieślał znaczenie tłumaczenia Pisma św., które powstało w tradycji Mojżeszowej. Problem współczesnego przelıładu Pisra św. równioz należy rozwi zzywać nie tyle za pośrednictwen pomocniczych dyscyplin biblijnych, ale przede wszystkim w werze Kościoła 1 jej aktualizacji; Innymi słowy w św1et1e Tradycji Kościoła. Po drugie, niezaleźnie od charakteru urag, wielu punktach zdezaktualizowanych, hilarlańskie wypowiedzi pod-

56 InPs 66,6, CSEL 22,273 . 
krésajz znaczenie tekstu oryginalnego lub dobrego przekładu Pisma sw. w odczytaniu jego sensu. Sw. IIllary liczył się z tekstem. Uogólniajac to stwierdzenie trudno sie zgodzić z powszechna dziś opintą, ze patrystyczna egzogeza była subiektywna; a jesili nawet taka sie niejednokrotnie nam ukazuje, to ma ona uzasadnienie nie tylko wuchu czasu, lecz równiez racjach teologieznych, jak na przykład u sir. Hilarego, w autorytecle Tradycjl.

$$
\text { Ks. En1l Stanula - Warszawa }
$$

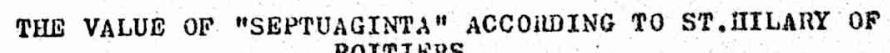
portiens

\section{/Summary/}

Analizing some of St.illlary's of Poltiers statements, included in the "Tractatus super Psalmos", wo come to the conolusion that the objective value of septuaginta depends on three things. First of all on the fact that it was established on Traditional belief. Secondly it was established before the birth of Christ and thirdy that $1 \mathrm{t}$ is of exegetic character. But nevertheless the fact that it was establisher within Traditional belice remalns the fundanental valuo of septuaginta. It was for this tradition that translators have done a competent work not only erow philological but also fron exegetic point of view. What rore, they have left a numbex of signs which according to IIl ary aim at interpreting the Bible. Because of this polnt of view Septuaginta's value rematns tireless. 